\title{
Identifying the energy gap in the German population using results from representative national health surveys (1985-2002)
}

\author{
Nanette Stroebele ${ }^{1, *}$, James O Hill ${ }^{2}$ and Stefan N Willich ${ }^{1}$ \\ ${ }^{1}$ Institute for Social Medicine, Epidemiology and Health Economics, Charité University Medical Center, Luisenstr. \\ 57, D-10117 Berlin, Germany: ${ }^{2}$ Center for Human Nutrition, University of Colorado Denver, Denver, USA
}

Submitted 5 August 2009: Accepted 23 February 2010: First published online 21 April 2010

\begin{abstract}
Objective: The prevalence of overweight and obesity is increasing in most countries, including Germany. The idea of estimating the population-wide energy gap that is likely responsible for the epidemic has recently been introduced and discussed. Design: Using published estimates of body weight from population-based data of national health surveys (1985-2002), the energy gap was calculated by estimating the distribution of the rate of weight gain within the German population (25-69 years of age) and the amount of excess energy storage that is responsible for this population-wide pattern of weight gain.

Setting: Germany.

Subjects: A representative sample of 26614 participants (12984 men, 13630 women). Results: The average annual weight gain was $0.22 \mathrm{~kg}$ for men and $0.32 \mathrm{~kg}$ for women over the 17 -year period. An estimated $90 \%$ of the population gained $<0.54 \mathrm{~kg} /$ year. Assuming that each kilogram of weight gained represents $32238 \mathrm{~kJ}(7700 \mathrm{kcal})$, the estimated energy accumulation was $19 \mathrm{~kJ}(4.64 \mathrm{kcal}) / \mathrm{d}$ in men and $28 \mathrm{~kJ}(6.75 \mathrm{kcal}) / \mathrm{d}$ in women aged 25-69 years. The distribution of estimated energy accumulation for $90 \%$ of the German population was $<50 \mathrm{~kJ}(12 \mathrm{kcal}) / \mathrm{d}$.

Conclusions: With an assumed energy efficiency of $50 \%$, the findings suggest that weight gain could be prevented in $90 \%$ of the German population with $<100 \mathrm{~kJ}$ $(24 \mathrm{kcal})$ reduction in energy intake or increase in energy expenditure per day. Theoretically, further weight gain might be prevented using a small-changes approach that emphasizes the importance of making small changes in physical activity and food intake.
\end{abstract}

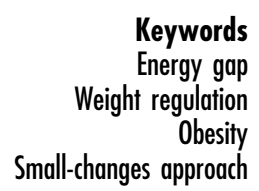

The prevalence of overweight and obesity is rising in all countries ${ }^{(1-4)}$, including Germany ${ }^{(5,6)}$. The WHO has declared overweight as one of the top ten risk conditions in the world and one of the top five in developed countries ${ }^{(7)}$. According to data from the Telephone Health Survey 2003, approximately $70 \%$ of adult men and $50 \%$ of women in Germany are currently overweight or obese ${ }^{(6)}$. Various studies have shown that excess weight contributes to CVD, some cancers and type 2 diabetes ${ }^{(8,9)}$. The current epidemic reflects a long-term upward shift in the distribution of BMI across all populations ${ }^{(10,11)}$. One explanation for the development of obesity is an energy imbalance caused by a combination of more sedentary lifestyles and an increase in consumption of energy (rich foods) ${ }^{(12-14)}$.

National surveys conducted in Germany between 1985 and 2002 showed an increase in the prevalence of obesity in both genders ${ }^{(18)}$, and according to the German National Health Interview and Examination Survey ${ }^{(15)}$ only $13 \%$ of the German adult population met the German guideline of being physically active three times per week for at least 30 min in 1998. A study conducted in Bavaria, Germany, revealed that fewer than a third of the 893 participants met the recommended physical activity levels and, in addition to reduced sports activities, obesity was also linked to increased television viewing and use of computers ${ }^{(16)}$. Furthermore, food consumption in the German population has changed over the years. Although there has been a positive increase in fish, poultry, vegetable and fruit consumption, there has also been an increase in sweets and fried potato dishes $^{(17)}$.

The first study to introduce the idea of a populationwide energy gap and its estimation model was that of Hill et $a l^{(19)}$. Using data from the National Health and Nutrition Examination Survey and the Coronary Artery Risk Development in Young Adults study ${ }^{(20)}$, they estimated the distribution of the rate of weight gain within the population over a period of 8 years. With the assumption of a gradual/linear rate of gain and that each pound of 
body weight equals $14644 \mathrm{~kJ}(3500 \mathrm{kcal})$, they calculated the annual energy accumulated. The estimated energy accumulation for $90 \%$ of the population was approximately $209 \mathrm{~kJ}(50 \mathrm{kcal}) / \mathrm{d}$. Thus, it was hypothesized that by some combination of increasing energy expenditure and reducing energy intake by $419 \mathrm{~kJ}(100 \mathrm{kcal}) / \mathrm{d}$, most of the weight gain in the US population could be prevented. In China, the estimated energy gap for the population was $188 \mathrm{~kJ}$ $(45 \mathrm{kcal}) / \mathrm{d}^{(21)}$. In Australia, using data from the Australian Longitudinal Study on Women's Health, an average weight gain of approximately $0.5 \mathrm{~kg}$ /year for women aged $45-55$ years was found, which equates to an energy imbalance of only approximately $42 \mathrm{~kJ}(10 \mathrm{kcal}) / \mathrm{d}^{(22)}$. In Swedish adults, the estimated energy gap was $34 \mathrm{~kJ}(8 \cdot 2 \mathrm{kcal}) / \mathrm{d}$ for men and $52 \mathrm{~kJ}(12 \cdot 4 \mathrm{kcal}) / \mathrm{d}$ for women ${ }^{(23)}$.

Müller and his colleagues ${ }^{(24)}$ used the same approach to calculate the energy gap in German children using actual measures of fat mass and fat-free mass to calculate energy gain. They found mean daily energy increases of $89 \mathrm{~kJ}(21 \cdot 2 \mathrm{kcal}) / \mathrm{d}$ in boys and $194 \mathrm{~kJ}(46 \cdot 4 \mathrm{kcal}) / \mathrm{d}$ in girls aged 10-14 years. The 90th percentile of energy gap in these children who became overweight was $301 \mathrm{~kJ}$ $(72 \mathrm{kcal}) / \mathrm{d}$ for girls and $223 \mathrm{~kJ}(53.2 \mathrm{kcal}) / \mathrm{d}$ in boys. The authors estimated that reductions in energy intakes of 419-586 kJ (100-140 kcal)/d should prevent overweight in German children.

The objective of the present study is to estimate the energy gap of the German adult population using results from national health surveys conducted between 1985 and 2003 by using the average weight gain over the 17year period and translating the $\mathrm{kg}$ (fat) into $\mathrm{kJ}$ (kcal) in order to calculate the estimated energy accumulation per year (and per day).

\section{Methods}

The published results from four national health surveys conducted between 1985 and 1998 (1984-1986, 1987-1988, 1990-1992 and 1998) ${ }^{(25,26)}$ were used for the analysis. Each cohort included between 2300 and 3700 participants, with a total of 22807 participants (11248 men and 11559 women). The German national health surveys (Bundesgesundheitssurvey, 'Federal Health Survey') were used to determine the health status of the German adult population. The surveys were conducted by the Robert KochInstitute on behalf of the German Ministry of Health. The data from the first two health surveys only include West Germany, and body weight and height were individually measured in a laboratory setting.

In addition, three surveys of the 'Bertelsmann Health Monitor' in 2002-2003 (Spring 2002, Fall 2002 and Spring $2003)^{(27)}$ with a total of 3707 participants (1736 men and 2071 women) were used. For data collection of the 'Bertelsmann Health Monitor', at each data point, approximately 50000 households across Germany were contacted and the three surveys were merged to report mean height and weight for 2002. The survey was used to obtain information and trends about the existing German health-care sector. Body weight and height were assessed using self-reported measures. Given the existing bias with regard to self-reported height and weight, both measures were adjusted accordingly using results from the national health survey 1984-1986, in which both direct and selfreported measures of height and weight were collected. More details about the adjustments can be found in Helmert and Strube ${ }^{(18)}$. All included samples were representative for the German population aged 25-69 years.

For the analysis, the published body weight data, separated by gender, of the seven health surveys reported in Helmert and Strube ${ }^{(18)}$ were used to estimate the energy gap in the German population.

\section{Results}

Men and women aged 25-65 years using the populationbased data from the surveys mentioned above were included to estimate the energy gap in the German population. Table 1 shows the body height, weight and BMI in men and women aged 25-69 years between 1985 and 2002.

Given these data and assuming a linear rate of gain, the average annual weight gain among men was $0 \cdot 22 \mathrm{~kg}$ and $0 \cdot 32 \mathrm{~kg}$ among women over the 17 -year period. Assuming weight gain is normally distributed, $90 \%$ of the population gained $<0.54 \mathrm{~kg} /$ year (for men $=0.49 \mathrm{~kg} /$ year; for women $=0.54 \mathrm{~kg} /$ year).

Assuming that each kilogram of weight gained represents $32238 \mathrm{~kJ}$ ( $7700 \mathrm{kcal})$, the estimated average energy accumulation is $19 \mathrm{~kJ}(4.64 \mathrm{kcal}) / \mathrm{d}$ in men and $28 \mathrm{~kJ}$ $(6.75 \mathrm{kcal}) / \mathrm{d}$ in women aged $25-69$ years. The distribution of estimated energy accumulation for $90 \%$ of the German population is $<50 \mathrm{~kJ}(12 \mathrm{kcal}) / \mathrm{d}$; men $=43 \mathrm{~kJ}$ $(10 \cdot 33 \mathrm{kcal}) / \mathrm{d}$; women $=48 \mathrm{~kJ}(11.40 \mathrm{kcal}) / \mathrm{d}$.

Since direct measures of energy cannot be used in large population studies, we used estimations of energy efficiency by Hill et $a l^{(19)}$ and Brown et $a l^{(22)}$. The authors assumed an energy efficiency of at least $50 \%$; meaning for every excess $419 \mathrm{~kJ}$ ( $100 \mathrm{kcal}$ ) consumed, at least $209 \mathrm{~kJ}$ $(50 \mathrm{kcal})$ of energy are deposited in energy stores. With an energy efficiency of approximately $50 \%$, the yearly weight gain in the German population could be prevented with $<100 \mathrm{~kJ}$ ( $24 \mathrm{kcal}$ ) reduction in energy intake or increase in energy expenditure per day in $90 \%$ of the population. Figure 1 shows the hypothetical weight gain projection for men and women in Germany with and without the $100 \mathrm{~kJ}$ ( $24 \mathrm{kcal}) / \mathrm{d}$ energy gap.

\section{Discussion}

In the present analysis, we estimated the annual energy accumulation of the German adult population using 
Table 1 Mean body height, weight and BMI of German adults (aged 25-69 years) by gender using national health surveys (1985-2002; $n$ 26614)*

\begin{tabular}{|c|c|c|c|c|c|c|c|}
\hline & \multirow[b]{2}{*}{$n$} & \multicolumn{2}{|c|}{ Height $(\mathrm{cm})$} & \multicolumn{2}{|c|}{ Weight $(\mathrm{kg})$} & \multicolumn{2}{|c|}{ BMI $\left(\mathrm{kg} / \mathrm{m}^{2}\right)$} \\
\hline & & Mean & SD & Mean & SD & Mean & SD \\
\hline \multicolumn{8}{|l|}{ Men } \\
\hline 1985 & 2398 & $174 \cdot 9$ & $7 \cdot 8$ & $81 \cdot 4$ & $12 \cdot 5$ & $26 \cdot 58$ & 3.55 \\
\hline 1987 & 2613 & $175 \cdot 3$ & $7 \cdot 0$ & $81 \cdot 5$ & $11 \cdot 7$ & $26 \cdot 51$ & $3 \cdot 49$ \\
\hline 1991 & 3604 & $175 \cdot 3$ & $7 \cdot 1$ & $82 \cdot 7$ & $12 \cdot 6$ & $26 \cdot 91$ & $3 \cdot 81$ \\
\hline 1998 & 2633 & $176 \cdot 3$ & $7 \cdot 1$ & $85 \cdot 0$ & $13 \cdot 0$ & $27 \cdot 35$ & $3 \cdot 88$ \\
\hline $2002 t$ & 1736 & $175 \cdot 3$ & $8 \cdot 4$ & $85 \cdot 2$ & $16 \cdot 1$ & $27 \cdot 68$ & $4 \cdot 76$ \\
\hline Difference 1985-2002 & & +0.4 & & $+3 \cdot 8$ & & $+1 \cdot 10$ & \\
\hline \multicolumn{8}{|l|}{ Women } \\
\hline 1985 & 2341 & $162 \cdot 6$ & $6 \cdot 8$ & $67 \cdot 7$ & $13 \cdot 0$ & $25 \cdot 64$ & $4 \cdot 69$ \\
\hline 1987 & 2636 & $162 \cdot 5$ & $6 \cdot 4$ & $68 \cdot 2$ & $13 \cdot 3$ & $25 \cdot 88$ & $5 \cdot 07$ \\
\hline 1991 & 3794 & $162 \cdot 6$ & $6 \cdot 6$ & $69 \cdot 6$ & $13 \cdot 8$ & $26 \cdot 35$ & $5 \cdot 27$ \\
\hline 1998 & 2788 & $163 \cdot 7$ & $6 \cdot 5$ & $70 \cdot 8$ & $13 \cdot 9$ & $26 \cdot 47$ & $5 \cdot 22$ \\
\hline $2002 \dagger$ & 2071 & $165 \cdot 3$ & $7 \cdot 3$ & $73 \cdot 1$ & $15 \cdot 9$ & $26 \cdot 81$ & $6 \cdot 01$ \\
\hline Difference 1985-2002 & & $+2 \cdot 7$ & & $+5 \cdot 4$ & & $+1 \cdot 17$ & \\
\hline
\end{tabular}

${ }^{*}$ Retrieved and modified from Helmert and Strube ${ }^{(18)}$.

tPooled means from all three 'Bertelsmann Health Monitor' surveys.

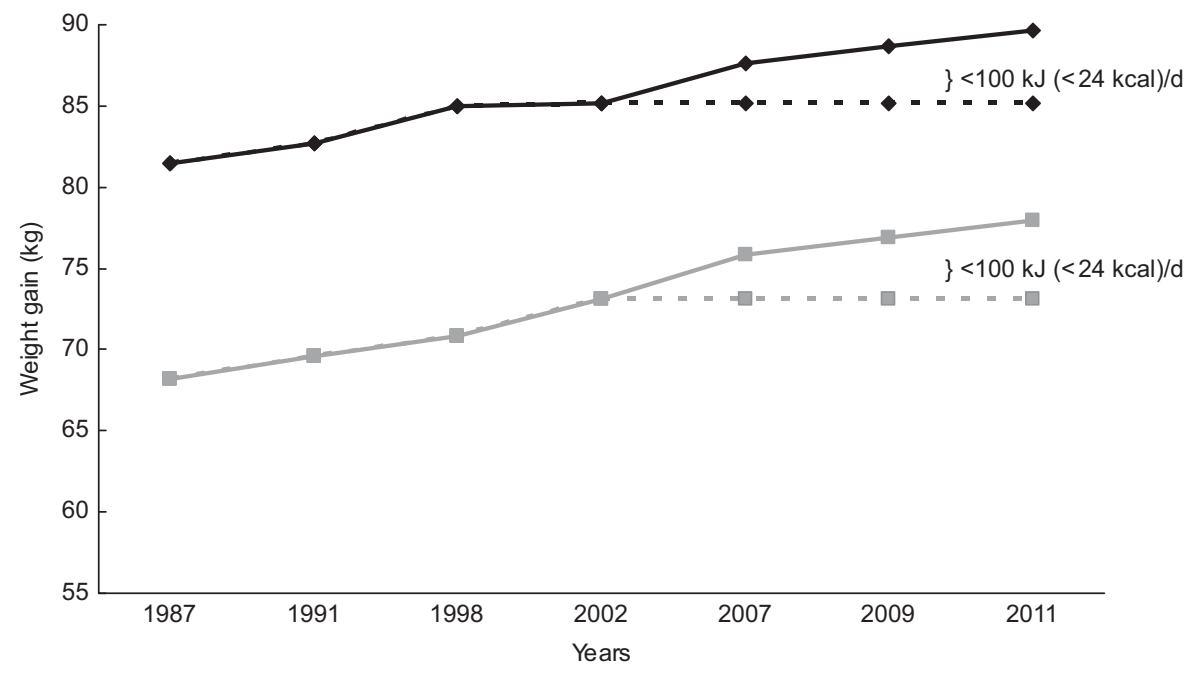

Fig. 1 Hypothetical weight projection by gender with and without the $100 \mathrm{~kJ}(24 \mathrm{kcal}) / \mathrm{d}$ energy gap. The solid lines indicate the projected weight gain in the population without any changes, whereas the dotted lines indicate weight maintenance with an energy gap of $<100 \mathrm{~kJ}(24 \mathrm{kcal}) / \mathrm{d}(-\bullet-$, men; - $\square$-, women $)$

cross-sectional population-based data from several representative surveys. We determined that by a combination of reducing energy intake minimally and increasing energy expenditure modestly further weight gain could be prevented in Germany.

Thus, the magnitude of this daily imbalance between energy intake and energy expenditure is estimated to be relatively small, with energy accumulations of approximately $63 \mathrm{~kJ}(15 \mathrm{kcal}) / \mathrm{d}$ accounting for weight gain in US population studies ${ }^{(19)}$ and even less for children ${ }^{(24,28)}$. However, this gap can lead to an annual weight gain of at least 2 pounds per year and 20 pounds in 10 years ${ }^{(19)}$.

Given the current prevalence of overweight and obesity in Germany and its rather notable increase in incidence per year, it is surprising that $90 \%$ Germans appear to gain only an estimated $\leq 50 \mathrm{~kJ}(\leq 12 \mathrm{kcal}) / \mathrm{d}$, compared to approximately $209 \mathrm{~kJ}(50 \mathrm{kcal}) / \mathrm{d}$ in $90 \%$ of the US population. German children (10-14 years) appear to be gaining more than adults ${ }^{(24)}$. For the German adult population, an approach that reduces energy intake by $100 \mathrm{~kJ}(24 \mathrm{kcal}) / \mathrm{d}$ could potentially prevent further weight gain in approximately $90 \%$ of the population and thus at least stabilize obesity rates. This equals $<100 \mathrm{~g}$ of fatreduced yoghurt or approximately $5 \mathrm{~min}$ of fast walking.

The use of population-based data collected by others limits the extent of the present analysis, and in general self-reported information is inferior to actual weight measurements. Given our lack of access to original data sets, we could not adjust for possible confounders such as changes in smoking status or socio-economic characteristics. In addition, using existing aggregated data does not allow for the adjustment of possible age or gender 
differences over the years. Since original data were not available, it was not possible to determine whether changes in age or gender distribution might exist and whether they might have influenced the changes in weight over the years.

However, we assume that the data used in the reference study adequately adjusted for potential confounders and sample distribution changes. It is also not the intention of the authors to calculate the precise caloric differences and weight changes of the German population over the years, but rather to point out that the estimated energy imbalance of this magnitude is in all likelihood a result of the increase in overweight and obesity in the population.

The energy gap concept of Hill et al. ${ }^{(19)}$ has been criticized as not accounting for the fact that obese individuals have accumulated more stored energy than lean individuals $^{(29)}$. Hill et al. ${ }^{(30)}$ clarify this by distinguishing between the energy gap for prevention of additional weight gain (which does not depend on stored energy) and the energy gap for maintenance of weight loss. The energy gap for the treatment of obesity is much larger due to the reduction in energy requirements after weight loss ${ }^{(30)}$. It is not suggested that this approach can restore the population to normal weight, but rather that it can stabilize obesity rates and prevent further weight gain.

It should be noted that in calculating the energy gap, Hill et al. ${ }^{(19)}$ used an energy efficiency of $50 \%$ for storage of excess energy in order to model the most conservative case. In reality, excess energy may be stored with greater efficiency under most conditions. If one assumes that the efficiency of storage of excess energy is $>50 \%$, the energy gap would be reduced.

Even though the energy gap is based on theoretical estimations and assumptions and empirical results are urgently necessary, we believe that the energy gap in the German population is still small and further weight gain could be prevented using the small-changes approach. This method emphasizes the importance of small increases in physical activity, as well as small decreases in food intake ${ }^{(19,31)}$. Both changes can be achieved with relatively minimal effort, for example walking approximately $1 \mathrm{~km} / \mathrm{d}$, which equals approximately $167 \mathrm{~kJ}$ ( $40 \mathrm{kcal}$ ) of energy expenditure or by reducing portion size modestly with each meal every day. There is already existing evidence that the small-changes approach can be effective. Dolan et al. ${ }^{(32)}$ and Bravata et al. ${ }^{(33)}$ show the feasibility and effectiveness of making small changes to increase physical activity. School and family programmes using the small-changes approach have also shown promising results ${ }^{(34-36)}$. In regard to dietary behaviour, Rolls et al. ${ }^{(37)}$ have consistently shown that decreases in energy density produce small reductions in energy intake. With the use of the small-changes approach, we believe that it might be possible to stabilize obesity rates in most populations.

We believe that making small changes to everyday living is more feasible and sustainable than big changes such as complete diet alterations or the transformation from a sedentary to a highly active lifestyle. In addition, our current environment does not support an active lifestyle. Small environmental changes could include various improvements such as more bike paths in cities, better public transportation systems or easier access to healthy foods in public places such as schools and cafeterias. In the United States, there are already initiatives by various entities such as the American Society of Nutrition, the Institute of Food Technology and the International Food Information Council, which support the small-changes approach and are ready to contribute to the goal of changing people's lifestyle behaviour in collaboration with the private sector and the government ${ }^{(31)}$. Given the rise in obesity rates in Germany, creating a German initiative with similar goals supported by various private and governmental institutions and stakeholders of different industries such as food supply or sporting goods is urgently needed. It is crucial that the public and private sector work together in order to create an environment that encourages people to make small changes towards a healthier lifestyle.

\section{Acknowledgments}

This research received no specific grant from any funding agency in the public, commercial or not-for-profit sectors. There are no conflicts of interest. N.S. and J.O.H. analysed the data and drafted and revised the manuscript. N.S. wrote the first draft of the manuscript. J.O.H. and S.N.W. made substantial contributions to the interpretation and writing of the manuscript and its revision.

\section{References}

1. Yoon KH, Lee JH, Kim JW et al. (2006) Epidemic obesity and type 2 diabetes in Asia. Lancet 368, 1681-1688.

2. Campbell $\mathrm{T} \&$ Campbell A (2007) Emerging disease burdens and the poor in cities of the developing world. $J$ Urban Health 84, i54-i64.

3. Wang Y \& Beydoun MA (2007) The obesity epidemic in the United States - gender, age, socioeconomic, racial/ethnic, and geographic characteristics: a systematic review and meta-regression analysis. Epidemiol Rev 29, 6-28.

4. Fezeu LK, Assah FK, Balkau B et al. (2008) Ten-year changes in central obesity and BMI in rural and urban Cameroon. Obesity 16, 1144-1147.

5. Statistisches Bundesamt (2006) Leben in Deutschland. Haushalte, Familien und Gesundheit - Ergebnisse des Mikrozensus 2005 (Living in Germany. Households, Families and Health - Results from the Micro census 2005). Wiesbaden, Germany: Statistisches Bundesamt.

6. Mensink GBM, Lampert T \& Bergmann E (2005) Übergewicht und Adipositas in Deutschland 1984-2003 (Overweight and obesity in Germany 1984-2003). Bundesgesundheitsblatt Gesundheitsheitsforschung Gesundheitsschutz 48, 1348-1356.

7. World Health Organization (2009) Regional Office for Europe. Highlights on health. http://www.euro.who.int/ eprise/main/ZZ_ToBeDeleted/CHH/SWE/chap2/20041123_4 (accessed July 2005).

8. Bergström A, Pisani P, Tenet V et al. (2001) Overweight as an avoidable cause of cancer in Europe. Int J Cancer 91, $421-430$. 
9. World Health Organization (2002) The World Health Report 2002: Reducing Risks, Promoting Healthy Life. Geneva: WHO.

10. Flegal KM, Carroll MD, Ogden CL et al. (2002) Prevalence and trends in obesity among US adults, 1999-2000. JAMA 288, $1723-1727$.

11. Dixon T \& Waters AM (2003) A Growing Problem: Trends and Patterns in Overweight and Obesity among Adults in Australia, 1980 to 2001. Bulletin no. 8. Canberra: Australian Institute of Health and Welfare.

12. Hill JO \& Peters JC (1998) Environmental contributions to the obesity epidemic. Science 280, 1371-1374.

13. Hill JO \& Melanson EL (1999) Roundtable consensus statement: overview of the determinants of overweight and obesity: current evidence and research issues. Med Sci Sport Exerc 31, S515.

14. French SA, Story M \& Jeffery RW (2001) Environmental influences on eating and physical activity. Annu Rev Public Health 22, 309-335.

15. Robert Koch-Institut, Statistisches Bundesamt (2007) Gesundheitsberichterstattung des Bundes. Gesundheit in Deutschland (Government Health Report. Health in Germany). Berlin: Robert-Koch-Institut.

16. Schaller N, Seiler H, Himmerich S et al. (2005) Estimated physical activity in Bavaria, Germany, and its implications for obesity risk: results from the BVS-II Study. Int J Behav Nutr Phys Act 2, 6.

17. Deutsche Gesellschaft für Ernährung (2008) Ernährungsbericht 2008 (Nutrition Report 2008). Bonn: Deutsche Gesellschaft für Ernährung.

18. Helmert U \& Strube H (2004) Trends in the development and prevalence of obesity in Germany between 1985 and 2002. Gesundheitswesen 66, 409-415.

19. Hill JO, Wyatt HR, Reed GW et al. (2003) Obesity and the environment: where do we go from here? Science 299 , 853-855.

20. Lewis CE, Smith DE, Wallace DD et al. (1997) Seven-year trends in body weight and associations with lifestyle and behavioural characteristics in black and white young adults: the CARDIA study. Am J Public Health 87, 635-642.

21. Zhai F, Wang H, Wang Z et al. (2008) Closing the energy gap to prevent weight gain in China. Obes Rev 9, Suppl. 1, 107-112.

22. Brown WJ, Williams L, Ford JH et al. (2005) Indentifying the energy gap: magnitude and determinants of 5-year weight gain in midage women. Obes Res 13, 1431-1441.

23. Berg C, Rosengren A, Aires N et al. (2005) Trends in overweight and obesity from 1985 to 2002 in Göteborg, West Sweden. Int J Obes 29, 916-924.
24. Plachta-Danielzik S, Landsberg B, Bosy-Westphal A et al. (2008) Energy gain and energy gap in normal-weight children: longitudinal data of the KOPS. Obesity 16, $777-783$

25. Forschungsverbund DHP (editor) (1998) Die Deutsche Herz-Kreislauf-Präventionsstudie. Design und Ergebnisse (The German Cardiovascular Prevention Study). Bern: Hans Huber.

26. Robert Koch-Institut (1998) Bundesgesundheitssurvey 1998. Erfahrungen, Ergebnisse, Perspektiven (German Federal Health Survey). Gesundheitswesen 61, 55-222.

27. Böcken J, Braun B \& Schnee M (editors) (2002) Gesundheitsmonitor 2002 (Health Monitor 2002). Die ambulante Versorgung aus Sicht der Bevölkerung und Ärzteschaft. Gütersloh: Bertelsmann Stiftung.

28. Wang YC, Gortmaker SL, Sobol AM et al. (2007) Estimating the energy gap among US children: a counterfactorial approach. Pediatrics 118, e1721-e1733.

29. Swinburn BA, Sacks G, Lo SK et al. (2009) Estimating the changes in energy flux that characterize the rise in obesity prevalence. Am J Clin Nutr 86, 1723-1728.

30. Hill JO, Peters JC \& Wyatt HR (2009) Using the energy gap to address obesity: a commentary. J Am Diet Assoc 109, 1848-1853.

31. Hill JO (2009) Can a small-changes approach help address the obesity epidemic? A report of the Joint Task Force of the American Society for Nutrition, Institute of Food Technologists, and the International Food Information Council. Am J Clin Nutr 89, 447-484.

32. Dolan MS, Weiss LA, Lewis RA et al. (2006) Take the stairs instead of the escalator: effect of environmental prompts on community stair use and implications for a national 'small steps' campaign. Obes Rev 7, 25-32.

33. Bravata DM, Smith-Spangler C, Sundaram V et al. (2007) Using pedometers to increase physical activity and improve health. JAMA 298, 2296-2304.

34. Stewart JA, Dennison DA, Lohl HW et al. (2004) Exercise level and energy expenditure in the Take 10! in-class physical activity program. J Sch Health 74, 397-400.

35. Rodearmel SJ, Wyatt HR, Barry M et al. (2006) A familybased approach to preventing excessive weight gain. Obesity (Silver Spring) 14, 1392-1401.

36. Rodearmel SJ, Wyatt HR, Stroebele N et al. (2007) Small changes in dietary sugar and physical activity as an approach to preventing excessive weight gain: the America On the Move family study. Pediatrics 120, 2869-2879.

37. Roll BJ, Drewnowski A \& Lediwke JH (2005) Changing the energy density of the diet as a strategy for weight management. J Am Diet Assoc 105, S98-S103. 